\title{
Data Access for the Social Sciences in Austria. Open Data, Closed Data, Research Infrastructures and Re-Use ${ }^{1}$
}

\section{Matthias Reiter-Pázmándy}

Austrian Federal Ministry for Education, Science and Research (BMBWF)

matthias.reiter-pazmandy@bmbwf.gv.at

\begin{abstract}
Open science and open access to research data are important aspects of research policy in Austria. In the last years, the social sciences have seen the building of research infrastructures that generate data and archives that store data. Data standards have been established, several working groups exist and a number of activities aim to further develop various aspects of open science, open data and access to data. However, some barriers and challenges still exist in the practice of sharing research data. One aspect that should be emphasised and incentivised is the re-use of research data.
\end{abstract}

\section{Keywords}

Open data, FAIR data, research infrastructures, research policy, social sciences, humanities

\section{Datenzugang für die Sozialwissenschaften in Österreich. Offene Daten, geschlossene Daten, Forschungsinfrastrukturen und Re-Use}

\section{Zusammenfassung}

Open Science und Open Access für Forschungsdaten sind wichtige Aspekte in der Forschungspolitik in Österreich. In den letzten Jahren wurden in den Sozialwissenschaften Forschungsinfrastrukturen, die Daten generieren, und Repositorien, die Daten archivieren, aufgebaut. Datenstandards wurden etabliert, mehrere Arbeitsgruppen existieren und eine Reihe an zukünftigen Aktivitäten zielen auf die Weiterentwicklung unterschiedlicher Aspekte von Open Science, Open Data und des Datenzugangs ab. Allerdings existieren weiterhin Hürden und Herausforderungen beim Teilen von Forschungsdaten in der alltäglichen Praxis. Ein Aspekt, der stärker in den Mittelpunkt gerückt und unterstützt werden sollte, ist die Nachnutzung von Forschungsdaten.

\section{Schlüsselwörter}

Open Data, FAIR Data, Forschungsinfrastruktur, Forschungspolitik, Sozialwissenschaften, Geisteswissenschaften

The author has declared that no competing interests exist.

I I would like to thank Stefan Hanslik for important suggestions. 


\section{As Open as Possible, as Closed as Necessary}

The debate on open science is currently a very lively one. There is an ever-growing body of scientific publications on the one hand and on the other hand strategies, recommendations and practical guidelines how to implement different aspects of open science by science policy advisory bodies, funders as well as from research organisations and data producers themselves.

Fecher/Friesike (2014) distinguish five schools in an attempt to structure different lines of the scientific and policy discourse. There is the infrastructure school with a view on open research and data infrastructures. The public school aims to make science more accessible to the public, as for instance through citizen science. The measurement school approaches open science through the lens of measuring science and its impact. The democratic school wants to make knowledge more freely available like in open data, and the pragmatic school focuses on collaboration among scientists.

In this article, I am approaching open science through the perspective of the infrastructure school, the democratic and the pragmatic school. My aim is not to give a complete overview about open science activities in Austria. A good overview about current lines of debate and action gives a recent issue of the Communications of the Association of Austrian Librarians (Blumesberger et al. 2019). It discusses various aspects of open science, from the perspective of national and European infrastructures, new ideas for incentives, perspectives from different (social sciences and humanities) disciplines and also challenges and barriers.

I rather would like to present a personal perspective with a background of experiences from the public administration. This view is building on my work in research policy for research infrastructures on the national and on the European level. I would like to highlight some current initiatives for better access to data in Austria in research policy and the social sciences community.

In research policy there is a widely shared perspective that for research open access to any kind of data is beneficial. The paradigm "as open as possible, as closed as necessary" is reflecting this. It also reflects the need for closeness in many ways, because of the necessities that come with high levels of data protection and privacy. It also reflects that in quantitative analysis of large datasets, researchers are not interested in specific individuals. They are interested in averages, in analysing patterns and correlations.

The aspect "as open as possible" is the guideline for a number of activities to open up the use of research data in the social sciences. For too long the traditional way of handling data in the social sciences has been to keep a dataset to oneself, to analyse it and then to put it away in a drawer. To individual researchers this has often been the most efficient and convenient way. Research policy has recognised this situation as a field of necessary action and put forward a number of activities to make datasets more widely available. This is a commonly shared position by many research policy makers: open (research) data is better. This view is also being shared by large parts of the research community itself. There are a number of arguments in favour of openness: higher quality, for instance through the potential for replication, more use of research outputs, therefore more knowledge creation, more transparency in terms of methods and process, more democracy, increasing visibility, increasing citation, more ways to look at a certain problem, more interdisciplinary research, and better use of tax payer's money. From this perspective, data can be even perceived as a commons, a public good.

\section{Developing Research Infrastructures in Austria}

Opening up data access has been going hand in hand with the development of archiving and data infrastructures. Austria has seen a process of catching up in this field in the last years. Archives for research data have become more available, active and visible. Three disciplinary archives in the social sciences and humanities have been at the centre of this development. ARCHE (A Resource Centre for Humanities Related Research in Austria) and GAMS (Geisteswissenschaftliches Asset Management System) are repositories for research data in the Digital Humanities with the latter focusing on digital editions. AUSSDA (Austrian Social Science Data Archive) is a repository for social science research data. All three archives received certification with the Core Trust Seal and are so far the only ones in Austria (Ernst et al. 2020). The certification is awarded by the international non-profit organization CoreTrustSeal. In its funding guidelines, the Austrian science fund FWF recommends researchers to opt for archives with this certificate. ARCHE, GAMS and AUSSDA are part of larger research infrastructure initiatives in Europe that bring together national data collection and archiving activities. AUSSDA is part of the Consortium of European Social Science Data Archives (CESSDA) contributing Austrian data to CESSDA's catalogue of 27.000 data sets. Another layer is being currently build on top of that with the aim of providing a single point of search for datasets across all scientific disciplines in Europe. Under the title European Open Science Cloud (EOSC) researchers and research infrastructure organisations are building an "internet of scientific data" with the support of the European Commission and the EU-Member States. To prepare Austria for the implementation of the EOSC and the participation in it, certain policy instruments to facilitate the participation of Austria have been established: the EOSC 
Support Office Austria will be coordinating Austria's participation in the legal entity, the EOSC partnership. The FAIR Office Austria will promote the application of FAIR principles in Austria that are a prerequisite for data storage in the EOSC framework.

The goals of research infrastructures and the open data movement go hand in hand well beyond archiving. Most research infrastructures do not have their focus on archiving, but on generating scientific data from observing or measuring different phenomena, like for instance the European Social Survey (ESS). In order to support activities that have been going on in the Austrian social science research infrastructure community in the last years, the BMBWF commissioned a network of institutions with the name PUMA (Plattform für Umfragen, Methoden und empirische Analysen), to put together an overview about the current state of affairs in the field of research infrastructures. In a series of workshops and interviews, a document was put together that maps the current situation and reflects what will be necessary in the coming years: the future strategy for social science research infrastructures in Austria (Zukunftsstrategie Sozialwissenschaftliche Forschungsinfrastrukturen Österreich 2020). It shows needs, important thematic fields and demand for social science research infrastructures in Austria. It points out where different disciplines and locations have overlapping demands. The aim was also to think further and to map future needs for infrastructures in Austria. The paper describes for instance the lack of an Austrian panel survey, more necessary initiatives in the growing field of experimental data and the continuation and expansion of Austria's participation in European research infrastructures. The future strategy should be understood as a common vision. It should also be used as a strategic policy document when different groups in Austria apply for funding in various contexts or when they negotiate for resources within their institutions for instance as part of performance agreements. Using it in the coming years as a map and guideline would increase its impact. The success of this strategic document will depend on whether social science in Austria will take it as reference of common disciplinary interests when developing their university's or research institution's profile in the field of infrastructure and when applying for funding at national or European level. A similar process is happening in the field of Digital Humanities. A mapping was put together in 2019 that gave an overview about the Digital Humanities and their needs in terms of research infrastructures (Mayer 2019). The community is currently developing a "Digital Humanities Austria Strategie 2O2I+" (CLARIAH-AT 2O2I) based on this process.

The commissioning of a mapping, the development of a bottom-up reference document, the use as an orientation tool for the research community, but also as stra- tegic document to refer to in institutional negotiations are necessary in this policy field and are part of an open collaboration process between research communities and administration. The research institutions are independent and free in their choice of research topics. Universities are in competition against each other for the best researchers and third-party funding. However, research infrastructures as complex and costly endeavours demand for coordinated action between institutions. When it comes to running large repositories, surveys or similar research infrastructures, there is a need to put resources together, to articulate common goals. And some activities of the future strategy for social science research infrastructures in Austria have already begun their way to implementation as a cooperation of four universities under the project name "Digitize!" (2020).

Another major development in open data is the policy by research funders to demand data sharing as part of their third-party funding. One of the milestones towards this expectation were the rules of the FWF for open access for research data (FWF 2019). This policy makes open access to research data mandatory for funded projects. An obligatory data management plan (DMP) should outline in more detail how data is being collected, archived and shared. This policy is one of the reasons for the judgement that Austria is making good progress towards the goals of open science.

\section{Future Activities for Data Access: Top-Down and Bottom-Up}

The Austrian government supports open science and data access for researchers with a number of activities. Measures in the field of open access, open data, open innovation and open source are listed in the current Austrian government programme (Bundeskanzleramt 202O). The Austrian Federal Ministry of Education, Science and Research (Bundesministerium für Bildung, Wissenschaft und Forschung, BMBWF) actively supports open science and pursues a number of activities to do so in the Austrian research landscape (BMBWF 202I). One of the main instruments were calls for funding for cooperative projects of Austrian universities, the Structural Funds for Institutions of Higher Education (Hochschulraumstrukturmittel, HRSM) and the call for "Digital and Social Transformation" of Austrian universities in 2020. A number of projects were focusing on open access. Especially in the latest call in 2020, FAIR research data was the focus of several projects. Three projects bundled under the title "Cluster Forschungsdaten" focus on research data and aim to build mechanisms in Austria that contribute to building the European Open Science Cloud (EOSC).

Another initiative to give researchers better access to data is in the field of closed data. The aim is better ac- 
cess to administrative or registry data for researchers. This initiative is part of a general ambition to improve research conditions in Austria. However, it should not be confused with open science activities as access to registry data should purposely be under very strict conditions and by definition not open. Registry data is of the highest sensibility and should be clearly separated from open data. However, this reform should be briefly outlined here as it will be of significant importance for social science research in Austria. In order to allow research with registry data under strict access conditions and in a highly secure environment, the government programme aims to establish an Austrian Micro Data Center (Bundeskanzleramt 2020, 216). Until now, Austria is lagging behind in access to registry data, a fact that has been criticised by the scientific community for a decade (Schwarz et al. 2O20) and recently by the OECD (2018). The Covid-I9 crisis has painfully highlighted this importance once again, as pointed out by researchers on many occasions (Oberhofer 2020). Important research on Austria's society is not possible and researchers have to look to other countries for data access. This has the disadvantageous effect that Austrian researchers work with data sets from Scandinavian countries, from Kazakhstan or Hungary, conducting their analysis and publications. Thus, insights into policy implications are gained for other countries but not for Austria. In addition, in some disciplines, as for instance in economics, publications in the highest-ranking journals are more and more based on administrative data. In these journals, Europe is falling behind the US, which has regulated its access in a much more science-friendly way (König/Schmoigl 2020, 7). Many conceptual and preparatory steps towards the implementation of the Austrian Micro Data Center have been taken already by the administration (Kogler 2020). The model for remote access should follow examples from Denmark or the Netherlands. After necessary legislative reforms, implementation is expected in 202I.

Besides the activities in the field or research infrastructures, several working groups are pushing Open Data further. Most prominent on the policy level are the Task Force PSI und Open Data (BMWD 2O2I) in the Austrian Federal Ministry for Digital and Economic Affairs (Bundesministerium für Digitalisierung und Wirtschaftsstandort, BMDW) and the "Cooperation Open Government Data Österreich" initiated by the Austrian Federal Chancellery together with the cities of Graz, Linz, Salzburg and Vienna. A number of other bottom-up networks and groups exist. They are well described in the "Recommendations for a National Open Science Strategy in Austria Open Science Network Austria OANA" (OANA, formerly known as Open Access Network Austria) by the working group Open Science Strategy (Mayer et al. 2020). OANA itself has been at the centre of activities in Austria and a main driver for many developments. One of the biggest achievements was the proclamation of the Vienna Principles on Scholarly Communication in 2016. The principles are all applicable on publication as well as research data, but the principles number three and four on reusability and reproducibility have an emphasis on data. OANA sees the transition to Open Science already underway in Austria. In the recommendations, OANA calls for developing a national Open Science strategy as previously suggested in a recommendation by the European Commission (2018) and in line with a requirement by the Public Sector Information (PSI) directive. In the PSI the European Commission (20I9, art. IO (I)) states that "Member States shall support the availability of research data by adopting national policies and relevant actions aiming at making publicly funded research data openly available ('open access policies'), following the principle of 'open by default' and compatible with the FAIR principles". In order to structure expectations towards datasets for sharing principles have emerged that are abbreviated as FAIR. Making data accessible should follow these principles: findable, accessible, interoperable and reusable. An open science strategy for Austria as described above is also expected to be published in 202I. Another set of requirements for data accessibility will come upon EU Member States with the wake of the proposal by the European Commission (2020) for a regulation on European data governance. This proposal with the title "Data Governance Act" is currently being negotiated. It aims at developing conditions for re-use of public sector data, including special conditions for closed data.

\section{Conclusio: Re-Using Data More Actively}

In Austria, the last years have seen the establishment of a general commitment, the building of institutions and the development of standards to advance open science. All these activities - building research infrastructures, establishing data archives, the developments in the field of standardization, the requirement to share data from third party funded projects, further plans to publish strategies - show that the general understanding that research data should be shared, has been established.

However, when it comes to applying all these principles in everyday practice, one still can observe a number of practical challenges. For instance, barriers in research culture exist. For Austria, a study on potential social science users of AUSSDA shows, that only a handful of research data from roughly 800 social science projects in Austria between 2016 and the beginning of 2019 had been actually archived (Prandner et al. 2019). Despite this evidence, the potential for data re-use still seems high in the social sciences and humanities community in Austria. In another survey on researchers' data usage 
habits $74 \%$ of Austrian researchers in the social sciences and $70 \%$ of researchers in the humanities stated that they already use data they have not collected themselves (Bauer et al. 2015, II2). In comparison to other disciplines, these values range in the middle.

One way to advance open data and data sharing could be a stronger emphasis on the re-use of data. Eventually, one of the aims of building infrastructures, archives and repositories is not only to store datasets, but also to give them a second life. However, re-use does not happen just by itself and there are reasons for it. Most importantly, more reputation is given to those using their own, new data collection. Also, researchers want to follow their own research interests and that is traditionally still attached to collecting one's own data as well. Furthermore, incentive structures of institutions are often not supporting data re-use.

To counter those factors that work detrimental to data sharing in today's research culture and institutions incentives are important. That is what future strategies could pay more attention to. Making data citable has been a necessary prerequisite, but now rewarding data citation could be one of the steps forward. Another focus could be to bring the two realms, open access and open (research) data, closer together. For instance, open access publications should always link to the datasets that have been used in the analysis leading to the article. Fostering these links need better recognition in policy documents and institutional strategies. A specific aspect of re-use is replication. Replication will gain importance and a debate has already started how to integrate replication activities in research proposals, projects, or in training, for instance at the doctoral level. In addition, journals might play a role in facilitating replication activities in the future. Last but not least, it needs a debate about the value of data re-use. When pushing for data re-use and incentivising it, in principle, a direction of research is already defined. This approach, its consequences and new research practices need to be discussed within the scientific community, just like the transition to Open Access is subject of current debates (König 2020, Laner 2020).

Data access for researchers and data sharing practices in the social sciences in Austria needs further improvement. As described in the article, some achievements have been made and many initiatives for further improvements are planned. Some initiatives are topdown driven by Ministries or by the European Commission, many initiatives and working groups are working bottom-up based in the scientific community. In the future, more attention should be given to re-using data. To get there, a debate is needed about incentives, but also a discussion within scientific communities about what incentivising re-use means for pathways of research, openness, replication and transparency.

\section{References}

Bauer, Bruno/Andreas Ferus/Juan Gorraiz/Veronika Gründhammer/Christian Gumpenberger/NikolausMaly/ Johannes Michael Mühlegger/José Luis Preza/Barbara Sánchez Solís/Nora Schmidt/Christian Steineder (2015), Forschende und ihre Daten: Ergebnisse einer österreichweiten Befragung: Report 2015. Version I.2, Internet: https://doi.org/I0.528I/zenodo.32043.

Blumesberger, Susanne/Andreas Ferus/Veronika Gründhammer/Barbara Sánchez Solis (2019), Schwerpunktthema "Open Science“, in: Mitteilungen der Vereinigung Österreichischer Bibliothekarinnen und Bibliothekare, Vol. 72(2), 224-23I, Internet: https://doi.org/Io.31263/ voebm.v72i2.330I.

$B M D W$ (202I), Bundesministerium für Digitales und Wirtschaftsstandort, Task Force Open Data and PSI, Internet: https://www.bmdw.gv.at/Themen/Europa/ OesterreichinderEU/Open-Data-und-PSI.html (access: I2.03.202I).

Bundeskanzleramt (2020), Aus Verantwortung für Österreich. Regierungsprogramm $2020-2024$, Internet: https://www.bundeskanzleramt.gv.at/bundeskanzleramt/die-bundesregierung/regierungsdokumente. html (access: 12.03.202I).

CLARIAH-AT (202I), Review draft of the strategy paper "Digital Humanities Austria Strategy 202I+. Four guiding principles for Digital Humanities in Austria“, Internet: https://igital-humanities.at/en/ dha/clariah-at (access: 12.03.202I).

Cluster Forschungsdaten (202I), Internet: https:// forschungsdaten.at (access: I2.03.202I).

Cooperation Open Government Data Österreich (202I), Internet: https://www.data.gv.at/infos/cooperation-ogdoesterreich (access: 12.03.202I).

Digitize! Computational Social Sciences in der digitalen und sozialen Transformation (2020), Internet: https:// digitize-transformation.at (access: I2.03.2O2I).

Ernst, Doris/Gertraud Novotny/Eva Maria Schönher (2020), (Core Trust) Seal your repository!, in: Mitteilungen der Vereinigung Österreichischer Bibliothekarinnen und Bibliothekare, Vol. 73(I), 46-59, Internet: https:// doi.org/I0.31263/voebm.v73ir.349I.

European Commission (2018), Recommendation (EU) of the Commission $2018 / 790$ of 25 April 2018 on access to and preservation of scientific information, Internet: https://eur-lex.europa.eu/legal-content/ EN/TXT/HTML/?uri=CELEX:32018Ho79o (access: I2.03.2O2I).

European Commission (2019), Directive (EU) 2019/1O24 of the European Parliament and of the Council of 20 June 2019 on open data and the re-use of public sector information, Internet: https://eur-lex.europa.eu/legal-content/EN/TXT/?uri=uriserv:OJ.L_.2OI9.I72.0I.0056.OI. ENG (access: 12.03.202I). 
European Commission (2020), Proposal for a regulation of the European Parliament and of the Council on European data governance (Data Governance Act), Internet: https://eur-lex.europa.eu/legal-content/ $\mathrm{EN} / \mathrm{TXT} /$ ? uri $=\mathrm{CELEX} \% 3 \mathrm{~A} 52 \mathrm{O} 2 \mathrm{OPCo} 67$ (access: I2.03.202I).

Fecher, Benedikt/Sascha Friesike (2014), Open science: One term, five schools of thought, in: Bartling Sönke/ Sascha Friesike (Eds.), Opening Science: The Evolving Guide on How the Internet is Changing Research, Collaboration and Scholarly Publishing, Champaign, IL: Springer, Internet: https://doi.org/IO.IOO7/978-3319-00026-8_2.

FWF (2019), Open Access to Research Data, Internet: https://www.fwf.ac.at/en/research-funding/openaccess-policy/open-access-to-research-data (access: I2.03.202I).

Kogler Sabine (2020), Registerdaten (Verwaltungsdaten) und ihre Nutzbarkeit für die Forschung - Status Quo und Ausblick, in: Hauer Werner (Hrsg.), Hochschulrecht. Jahrbuch 2020, Wien: NWV, 384-404.

König, Thomas (2020), Converting to Open Access. The Austrian Journal of Political Science (OZP) as a case study, in: Austrian Journal of Political Science, Vol. 49(3), I-6, https://doi.org/I0.15203/ozp.3184.vol49iss3.

König, Thomas/Lukas Schmoigl (2020), Erfolgreiche Registerforschung in Österreich. Welchen Mehrwert generiert die reglementierte Öffnung von Registerdaten für die wissenschaftliche Forschung? Eine Darstellung anhand von drei Beispielen, Internet: https://irihs.ihs.ac.at/id/eprint/5576 (access: I2.03.202I).

Laner, Barbara (2020), Open Access Transition: A view through the lens of a librarian, in: Austrian Journal of Political Science, Vol. 49(4), I5-20, https://doi. org/IO.I5203/ozp.3552.vol49iss4.

Mayer, Katja (2019), Digital Humanities in Österreich. Ergebnisse der Studie „Exploratives Mapping“. Technischer Bericht, Internet: http://repository.fteval.at/ id/eprint/5I4.

Mayer, Katja/Katharina Rieck/Stefan Reichmann/Patrick Danowski/Anton Graschopf/Thomas König/Peter Kraker/Patrick Lehner/Falk Reckling/Tony Ross-Hellauer/ Daniel Spichtinger/Michalis Tzatzanis/Stefanie Schürz (2020), Empfehlungen für eine nationale Open Science Strategie in Österreich / Recommendations for a National Open Science Strategy in Austria, Internet: https://doi.org/I0.528I/zenodo.4I09242.

Oberhofer, Harald (2020), Gekommen, um zu bleiben? Covid-I9 zeigt, wie wichtig quantitative Wissenschaften sind, in: Wiener Zeitung, 19.03.2020, Internet: https://www.wienerzeitung.at/meinung/ gastkommentare/2054995-Gekommen-um-zubleiben.html (access: 12.03.2021).

Prandner, Dimitri/Otto Bodi-Fernandez/Franz Höllinger/ Ahmed Tabakovic (2019), Forschungsinfrastruktur für empirische Sozialforschung in Österreich - Zwischen Anspruch und Bedarf, in: Österreichische Zeitschrift für Soziologie, Vol. 44, 79-89, Internet: https:// doi.org/IO.IO07/sII6I4-019-00324-9.

Schwarz, Gerhard/Thomas König/Harald Oberhofer/Michael Strassnig (2020), Zugang zu Register- und Individualdaten für die wissenschaftliche Forschung in Österreich, in: fteval JOURNAL for Research and Technology Policy Evaluation, Vol. 50, II-15, https://doi. org/I0.22163/fteval.2020.464.

Vienna Principles. A Vision for Scholarly Communication (2016), Internet: https://viennaprinciples.org (access: I2.03.2O2I).

Zukunftsstrategie Sozialwissenschaftliche Forschungsinfrastrukturen Österreich (2020), Internet: https://www. puma-plattform.at/fileadmin/user_upload/p_puma/ Strategie/Strategiepapier_I6.7.2020.pdf (access: I2.03.2O2I).

\section{Author}

Matthias Reiter-Pázmándy works at the Austrian Federal Ministry for Education, Science and Research as Deputy Head of Department for Social Sciences and Humanities representing Austria in several committees of European research infrastructures and the European research framework programme Horizon Europe. The views expressed in the article are his own. 